\title{
Fine Particles and Mortality
}

\author{
Suresh H. Moolgavkar \\ Fred Hutchinson Cancer Research Center Seattle, Washington, USA
}

In an interesting paper in a recent issue (vol 17, issue 14) of the journal, Enstrom examined the association between fine particulate matter (PM) pollution and mortality in a cohort of elderly Californians. The analyses used proportional hazards regression and after adjusting for age, sex, cigarette smoking, and other potential confounders, Enstrom concluded, "These epidemiologic results do not support a current relationship between fine particulate pollution and total mortality in elderly Californians, but they do not rule out a small effect, particularly before 1983." Enstrom's analyses were based on a subcohort of individuals enrolled in the first Cancer Prevention Study (CPS I) conducted by the American Cancer Society (ACS). Enstrom's conclusion is consistent with the conclusions of a cohort study among veterans conducted by Lipfert et al. (2000), but is at odds with the results from analyses of the second ACS cohort (CPS II) by Pope and others (Pope et al., 1995, 2002; Krewski et al., 2000), which reported statistically significant associations between fine particulate pollution and mortality.

Every epidemiological study has weaknesses and limitations and, undoubtedly, both proponents and skeptics of the 'fine particles cause death' thesis will find much to criticize in the studies that do not support their conclusions. These discrepant results raise an important question, however. Can contemporary epidemiological and statistical tools reliably detect miniscule risks, particularly with strong risk factors as potential confounders? All the cohort studies referred to above use proportional hazards modeling for data analyses. But is proportional hazards really the appropriate tool for these analyses? First, it is highly unlikely that proportionality of hazards would hold over the entire period of time covered by these studies. Statistical tests for departures from proportionality of hazards have low power. Enstrom states that, in his analyses, these tests failed to reject proportionality of hazards. However, his finding of a higher relative risk associated with fine particles over the period 1973-1982 is inconsistent with proportionality of hazards over the entire

Address correspondence to S. H. Moolgavkar, Fred Hutchinson Cancer Research Center Seattle, WA 98109, USA. E-mail: smoolgav@fhcrc.org period of the study. Even if proportionality of hazards were to hold for exposure to fine particles, we know that it most definitely does not hold for cigarette smoking, a strong risk factor and a potential confounder of the PM mortality association. For example, we know that, for a given daily level of smoking, the relative risk of lung cancer is strongly dependent on duration of smoking. Moreover, when smokers quit, the relative risk for mortality declines over a period of many years, and not virtually instantly as is assumed by proportional hazards. What influence does this manifestly incorrect model for a strong confounder have on the estimates of air pollution effects? Similarly the use of a proportional hazards model to adjust for age of entry into studies is also suspect.

I have discussed the original CPS II study (Pope et al., 1995) and reanalyses (Krewski et al., 2000; Pope et al., 2002) in detail elsewhere (Moolgavkar, 2005). I note here, however, that the reanalysis by Krewski et al. (2000) of the original (Pope et al., 1995) study (which considered no pollutant other than $\mathrm{PM}$ ), showed quite clearly that the pollutant most strongly associated with mortality was not $\mathrm{PM}$ but $\mathrm{SO}_{2}$. In fact, when $\mathrm{SO}_{2}$ was considered along with PM in the model for all-cause mortality, the coefficient for sulfates was reduced to less than a third of its original value, that for fine particles was reduced to a sixth of its original value, and both became statistically insignificant. It is also of interest to note that consideration of spatial correlations attenuated the PM coefficients to a much greater extent than the coefficients for $\mathrm{SO}_{2}$. Given the much stronger and more robust association of $\mathrm{SO}_{2}$ with mortality in the CPS II reanalyses, I find it surprising that this study continues to be taken as providing strong support for the PM mortality association. It can be plausibly argued on biological grounds that $\mathrm{SO}_{2}$ could not be causally associated with mortality. But that still does not explain why $\mathrm{SO}_{2}$ wipes out the $\mathrm{PM}$ signal in joint pollutant models. This awkward fact has simply been dismissed as being irrelevant. In a more recent study of the CPS II cohort that doubles the follow-up time and triples the number of deaths, Pope et al (2002) reported significant associations between fine particles and oxides of sulfur with all-cause, cardiovascular and lung cancer mortality. Surprisingly, despite the findings in the Krewski analyses that $\mathrm{SO}_{2}$ was the pollutant most strongly associated with mortality, no joint pollutant analyses were carried 
out. I wonder how this oversight was missed by the referees of the journal in which this paper appeared. In any case, this paper leaves unaddressed the question of which of the two pollutant classes is more strongly associated with mortality, which is probably the single most important question raised by the Krewski reanalyses of the CPS II study. In view of the association of $\mathrm{SO}_{2}$ with mortality in the CPS II study and in time-series studies in Los Angeles (Moolgavkar, 2000), it would be of interest to see Dr. Enstrom's analyses extended to include other pollutants.

Despite my skepticism regarding the use of proportional hazards models for analyses of cohort studies of small risks, these models provide useful and flexible tools for the analyses of epidemiological data. However, I believe that systematic investigation is required to understand the properties of the model when the basic assumptions are violated, particularly when the model is used to detect small risks in the presence of strong confounders. Unfortunately, biological understanding has not kept pace with the increasingly sophisticated statistical tools used in air pollution epidemiology, particularly in time-series studies. The interpretation of meta-analyses using hierarchical Bayesian techniques is, in my view, particularly problematic. Yet, the results of such analyses continue to appear, not in specialized statistical or epidemiological journals where they belong, but in mainstream medical journals. The readership of these journals is unable to evaluate critically the arcane methodology used in the analyses and must accept the results on faith, trusting, in ef- fect, that the editors have chosen impartial and knowledgeable reviewers.

\section{REFERENCES}

Enstrom, J. E. 2005. Fine particulate air pollution and total mortality among elderly Californians, 1973-2002. Inhalation Toxicol. 17.

Krewski, D., Burnett, R. T., Goldberg, M. S., Hoover, K., Siemiatycki, J., Jerrett, M., Abrahamowicz, M., White, W. H. 2000. Reanalysis of the Harvard Six Cities study and the American Cancer Society study of particulate air pollution and mortality. A special report of the Institute's Particle Epidemiology Reanalysis Project. Cambridge, MA: Health Effects Institute.

Lipfert, F. W., Perry, H. M., Jr., Miller, J. P., Baty, J. D., Wyzga, R. E., Carmody, S. E. 2000. The Washington University-EPRI veterans' cohort mortality study: preliminary results. In: Grant, L. D., ed. PM2000: particulate matter and health. Inhalation Toxicol. 12:4173.

Moolgavkar, S. H. 2000. Air pollution and mortality in Three U.S. Counties. Environ. Health Perspect. 108:777-784.

Moolgavkar, S. H. 2005. A review and critique of EPA's rationale for a fine particle standard. Regulatory Toxicol. Pharmacol. 42:123-144.

Pope, C. A., III, Thun, M. J., Namboodiri, M. M., Dockery, D. W., Evans, J. S., Speizer, F. E., and Heath, C. W., Jr. 1995. Particulate air pollution as a predictor of mortality in a prospective study of U.S. adults. Am. J. Respir. Crit. Care Med. 151: 669-674.

Pope, C. A., III, Burnett, R. T., Thun, M. J., Calle, E. E., Krewski, D., Ito, K., and Thurston, G. D. 2002. Lung cancer, cardiopulmonary mortality, and long-term exposure to fine particulate air pollution. JAMA 287:1132-1141. 